\title{
Solving the impossible: the puzzle of coherence, consistency and law
}

\author{
Stephen Pethick
}

\author{
University of Kent
}

\begin{abstract}
$\underline{\text { Abstract }}$
Though considerable claims are made for the use of coherence in law, its meaning is routinely taken to be elusive, controversial or even mystical. Some argue that defining coherence is logically impossible. This is surprising at best, and at worst should prompt serious alarm. It is generally agreed, at least, that consistency provides one necessary condition for coherence, though the list of additional elements required is keenly disputed. I pitch the dispute further back, and argue that the agreed-upon relation with consistency is unsustainable and damaging, and arises only because of a striking methodological oversight. This oversight accounts for and resolves the perceived impossibility and complexity of coherence. Freed from consistency, I argue for coberence just as "sticking together", and close by considering the implications of my analysis for writing that presently presses coherence into legal service.
\end{abstract}

The concept of coherence and its practical utility in reference to the legal system and legal argumentation are still very far from showing unanimity and precision of content and definition.... (Zaccaria, 1990)

A further puzzle ... has its roots in the fact that coherence theorists have been unable to reach anything like a consensus on how to define their central notion. ${ }^{2}$ (Olsson, 2005)

1 G Zaccaria, "Hermeneutics and narrative comprehension in law" in P Nerhot (ed.), Law, Interpretation and Reality (Dordrecht, Netherlands: Kluwer, 1990), p. 265.

2 E Olsson, Against Coherence: Truth, probability and justification (Oxford: OUP, 2005), p. viii. 


\section{One}

$\mathrm{I}^{\mathrm{r}}$ law, the ascendancy of coherence has been as unobtrusive as it is complete; look, and suddenly it is everywhere, extolled for its practical and jurisprudential value in any one of a multitude of legal applications. ${ }^{3}$ Indeed, such is the present standing of coherence that retrospectives of the concept are starting to emerge in legal historical scholarship. ${ }^{4}$ And yet, despite the now bewildering number of applications in which it is invoked, and despite the grave legal significance of the outcomes that are claimed for its employment, nobody has been able to agree what coherence actually is.

Naturally enough, the difficulty encountered in setting down the meaning of the concept has been leapt upon by those sceptical of the claims made for it in application, for it can scarcely be solid ground to employ coherence in, say, reasoning to a verdict of guilt on a capital charge, 5 if coherence itself remains an "elusive", "complex", or even "mystical" notion. ${ }^{6}$ Indeed, the small legion of its detractors is now so confident that one writer recently proclaimed (in a monograph entitled Against Coberence) that "defining coherence is logically impossible". ${ }^{7}$ However, the persistent difficulty with the concept is not only recorded by those hostile to its use; in fact, doubts about the meaning of coherence have most frequently been articulated by those urging its application - even if these doubts often lie buried within the detail of the application in question. ${ }^{8}$ Plainly, all of this ought properly to give practitioners and scholars alike serious pause when contemplating the employment of coherence, such that there is now a clear burden upon the supporters of a coherence

3 See, e.g. R Alexy and A Peczenik, "The concept of coherence and its significance for discursive rationality" (1990) 3(1) Ratio Juris 130-47; J M Balkin, "Understanding legal understanding: the legal subject and the problem of coherence" (1993) 103 Yale LJ 105; R Dworkin, Law's Empire (Cambridge, Mass; Harvard UP, 1986); K Gunter, "A normative conception of coherence for a discursive theory of legal argumentation", (1989) 2 Ratio Juris 155-66; J Hage, "Law and coherence" (2004) 17 Ratio Juris 87-105; S L Hurley, "Coherence, hypothetical cases, and precedent" (1990) 10 Oxford Journal of Legal Studies 221-51; B Jackson, "The normative syllogism and the problem of reference" in P Nerhot (ed.), Law, Interpretation and Reality (Dordrecht, Netherlands: Kluwer, 1990), pp. 379-401; K Kress, "Coherence" in D Patterson (ed.), A Companion to the Philosophy of Law and Legal Theory (Oxford: Blackwell, 1996), pp. 533-52; N MacCormick, Legal Reasoning and Legal Theory (Oxford: Clarendon, 1978); N MacCormick, "Coherence in legal justification" in A Peczenik et al. (eds), Theory of Legal Science (Dordrecht: Kluwer, 1984), pp. 235-51; N MacCormick, Rhetoric and the Rule of Law (Oxford: OUP, 2005); J Morgan, "Tort, insurance and incoherence" (2004) 67(3) Modern Law Review 384-401; J Raz, "The relevance of coherence", in Ethics in the Public Domain (Oxford: OUP, 1994), pp. 277-325; V Rodriguez-Blanco, "A revision of the constitutive and epistemic coherence theories in law" (2001) 14(2) Ratio Juris 212-32; A Schiavello, "On 'coherence' and 'law': an analysis of different models" (2001) 14(2) Ratio Juris 233-43; L M Soriano, "A modest notion of coherence in legal reasoning: a model for the European Court of Justice" (2003) 16(3) Ratio Juris 296-323; E Weinrib, The Idea of Private Law (Cambridge, Mass: Harvard, 1995).

4 See M Walters, "Legal humanism and law as integrity" (2008) 67(2) Cambridge Law Journal 351-75.

5 See MacCormick, "Coherence" (n. 3 above), pp. 245-7, who uses the infamous brides-in-the-bath English murder case (R v Smith (1915) 11 Cr App R, 229) in careful illustration of the importance of coherence in reasoning to justified conclusions using circumstantial evidence alone. Smith was convicted and hanged on 13 August 1915.

6 See J Sinclair, Corpus, Concordance, Collocation (Oxford: OUP, 1991), p. 102, noting that coherence is "a rather mystical notion".

7 See Olsson, Against Coherence (n. 2 above), p. 137 (italics in the original). The attack on coherence has prompted an equally trenchant retaliatory literature; see, e.g. W Meijs and I Douven, "On the alleged impossibility of coherence" (2007) 157 Synthese 347-60.

8 Thus, Bonjour's observation is typical, writing of attempts to define coherence that "the main work of giving such an account, and in particular one which will provide some relatively clear basis for comparative assessments of coherence, has scarcely been begun, despite the long history of the project"; L Bonjour, The Structure of Empirical Knowledge (Cambridge, Mass: MIT, 1985), pp. $93-4$ (italics in the original). BonJour's attention to the meaning of coherence, in this seminal work on coherence and justification, begins only at p. 93, and even there he notes, as an addendum to the preceding quotation: "My response to this problem, for the moment at least, is a deliberate - though, I think, - justified, evasion." 
approach to identify with some precision what coherence amounts to, or risk the rejection of its application altogether. ${ }^{\text {? }}$

My aim in this paper is to move towards the clear understanding of coherence that is rightly demanded for its application. However, I undertake this project in an unconventional way, by first attacking one of the few features of coherence that is routinely agreed upon by its supporters and detractors alike, that consistency is necessary for coherence, though insufficient for it. Fortunately, the attack turns out to be constructive, as the dismissal of this relation helps clear the way for the "more general and precise account of coherence"10 sought throughout the literature. It does so because analysis of the relation exposes a striking methodological oversight under which all of the frustrations about coherence can be accounted. But here I need to add a significant caveat: I do not propose by this means to uncover the true nature of coherence (whatever that might look like). ${ }^{11}$ Instead, I aim to show that preoccupation with consistency has unwittingly caused impassable difficulties in the provision of a precise and usable account of coherence, and that its rejection immediately helps resolve the strange conceptual frustrations that are recorded otherwise in the literature. My method thereby employs an internal critique, and to the extent that it trades on some or other aspect of philosophy of language, this will be just what is also accepted by the work that I investigate. ${ }^{12}$

I begin, in section Two, by setting out both the perceived complexity of coherence and the precise modal relation between coherence and consistency articulated in legal writing and elsewhere. In section Three, I try to show that the relation is unsustainable, and then provide an explanation for its present popularity. This explanation will turn out to be crucial to the prospect of finding the better account of coherence that is sought in the literature. The section closes with a proposal for such an account, aiming at an understanding that is general and clear, and which fits our present linguistic and intuitive practice. In the final section, Four, I suggest some implications of the preceding commentary, considering in general terms its utility in relation to the present literature on coherence and law, and examining one case in particular in which its application can claim to have material legal impact.

\section{Two}

To plunder a line from Donald Davidson, in comparison to coherence, consistency is a "beautifully transparent" notion, ${ }^{13}$ and so there should be little surprise that the former concept has come to be articulated by reference to the latter. There is certainly no doubt that coherence has been found complex and multifaceted. Ken Kress's observation is typical, writing that, in law,

[normative] theories differ over whether reconstruction aims at coherence alone, or also at moral and political values. If other values are included, how are they combined with coherence? The best combination of coherence and morality? The morally best reasonably coherent theory? The most coherent,

9 Thus Millgram writes: "A coherence concept that the troops cannot use in the field is also one whose adoption it will be next to impossible to justify."; E Millgram, "Coherence: the price of the ticket" (2000) 97(2) The Journal Of Philosophy 83.

10 P Thagard, Coherence in Thought and Action (Cambridge, Mass: MIT, 2000), quoting from p. xii.

11 In fact, my sympathy here is with pragmatism, not realism; see section Three, below.

12 That is, principally, that predicates are capable of disambiguation from whatever they are predicated of hence the quest in the literature for a clearer, more general account of the concept (to be used in comparative assessment across the range of its use), and hence the frustration at the perceived elusiveness of such an account (see sections Two and Three below).

13 D Davidson, "A coherence theory of knowledge and truth" in E Lepore (ed.), Truth and Interpretation (Oxford: Blackwell, 1986), p. 309. In fact, Davidson notes that truth is beautifully transparent in comparison to coherence! 
reasonably moral theory? The most important differences are over what coherence itself means. ${ }^{14}$ [italics in original]

And Jonathan Morgan comments in his paper, "Tort, insurance and incoherence": "Legal coherence, one would have thought, must be shared as a universal aspiration by lawyers (and even legal philosophers) .. Q Quite what 'coherence' requires, however, is immensely controversial."'15

Indeed, the glut of conceptions of coherence - and the controversy attending them dogs the literature, and this has lead BonJour and others to lament that "a better account of coherence is beyond any doubt something devoutly to be sought". ${ }^{6}$ Hence, in a paper as early as 1984, MacCormick set out as his principle aim "to elucidate this elusive notion of 'coherence', of 'hanging together', of 'making sense"'.17

But, in spite of this and other attempts to resolve the controversy, the frustrations in law remain, and nor does there appear to be a prospect of importing a solution from any other discipline. Thus, in a recent special edition of New Literary Theory devoted entirely to coherence, Colomb and Griffin write that "Coherence is a more complex, more ubiquitous, and in many ways less accessible phenomenon than our intuitions and scholarship ever led us to believe." 18 And Barry Allen adds: "Coherence is not one thing. That doesn't make it incoherent, although it rules out a conceptual definition."19 The same dissatisfaction is recorded in many other fields, too, Bublitz, for example, writing in linguistics that "Coherence is a concept which in its complexity is still not fully understood and a matter of continuing debate [sic]." 20

Regardless of disputes concerning the complete account of coherence, one matter is more or less settled; consistency is necessary, but insufficient, for it. The relevant relation is exemplified in BonJour's note that,

A serious and perennial mistake in discussing coherence, usually committed by critics but occasionally also by would-be proponents of coherence theories, is to assume that coherence means nothing more than logical consistency, the absence of explicit contradiction. It is true that consistency is one requirement of coherence, that inconsistency is a very serious sort of incoherence. But it is abundantly clear, as many coherentists have pointed out, that a system of beliefs might be perfectly consistent and yet have no appreciable degree of coherence. ${ }^{21}$

Dancy writes similarly in Contemporary Epistemology, where he describes the views of "coherentists" under the general title, "What is coherence?":

14 See Kress, "Coherence” (n. 3 above), p. 537.

15 See Morgan, “Tort” (n. 3 above), p. 395.

16 BonJour, The Structure (n. 8 above), at p. 94.

17 See MacCormick, "Coherence” (n. 3 above), p. 235. MacCormick's influential paper has been hugely successful in articulating the notions of "normative coherence" and "narrative coherence", but - perhaps surprisingly - this has not helped produce a better understanding of coherence itself: the general reason for this is set out in section Three below.

18 G Colomb and J Griffin, "Coherence on and off the page: what writers can know about writing coherently" (2004) 35 New Literary Theory 273-301, p. 275.

19 B Allen, "The ubiquitous artefact: on coherence" (2004) 35 New Literary Theory 259-71, p. 259.

20 W Bublitz, "Introduction: views of coherence" in W Bublitz, U Lenk and E Ventola (eds), Coherence in Spoken and Written Discourse (Amsterdam: John Benjamins, 1999), p. 1.

21 BonJour, The Structure (n. 8 above), p. 95. MacCormick picks up this point in relation to law, demanding "Why is it that a set of legal norms might sometimes appear incoherent, even when as a set they are not inconsistent?"; MacCormick, Rhetoric (n. 3 above), p. 190. 
All coherentists agree that consistency is a necessary condition for coherence. Bradley added that a coherent set should be complete or comprehensive in some sense ... But consistency and completeness were not enough; they did not capture the feeling that a coherent set stuck together or fitted in a special way. To capture this, classical coherentists use the notion of entailment ... 22

Alcoff, also writing within epistemology, notes similarly that "Some minimalist formulations of coherence require only simple consistency, while other, stronger versions require mutual entailment", 23 while Grayling writes, directly under the section title, "The character of coherence":

In general, the coherence notion has the following overall character. Because truth is to be determined by means of a test of "coherence" somehow specified, the question of a proposition's value turns on its relations with other propositions in a set, and accordingly the notion of a context or system plays a vital role in the account we are to give of truth. The notion of a system, in turn, is to be made out in terms of consistency, connectedness, and completeness, and it is these ideas which need to be specified precisely if the theory is to recommend itself. ${ }^{24}$

Bertea, meanwhile, observes that,

Coherence is an inherently elusive and slippery notion ... While there is wide agreement among contemporary legal theorists on the characterization of coherence in the negative as lack of inconsistencies, it is still a question how coherence might be defined in positive terms. Coherence is generally held to be something more than logical consistency of propositions. But it is not clear exactly what this "something more" amounts to. 25

Zaccaria concurs, drawing a similar picture of the necessary but insufficient contribution of consistency:

With Aarnio, Peczenik and Alexy, one might say that the principle of coherence may be regarded as including the principle of consistency as a negative aspect, in the sense that the absence of logical self-contradictoriness . . . is a necessary, but not sufficient condition for there to be coherence. ${ }^{26}$

He adds, however:

Though moving within the broad framework constituted by the extended consideration of coherence which, especially as put forward by Aarnio, Alexy and Peczenik, covers the range of hypotheses going from formal logical derivation to consistency, we shall here refer to the theses of the author who, in the contemporary debate so far, has perhaps given the clearest, most circumstantial presentation, namely Neil MacCormick. ${ }^{27}$

Yet, even in the preferred work in question, the core idea is once more affirmed. Hence MacCormick expresses there the necessity but insufficiency of consistency, just as follows:

Coherence in reasoning is one important test of its soundness in reasoning. It is a test which is not fully satisfied by mere consistency, in the absence of self-

22 J Dancy, Contemporary Epistemology (Oxford: Blackwell, 1985), p. 110.

23 L Alcoff, Real Knowing: New versions of the coherence theory (Ithaca: Cornell, 1996), p. 5.

24 A C Grayling, An Introduction to Philosophical Logic 2nd edn (Oxford: OUP, 1997), p. 135.

25 S Bertea, "The arguments from coherence: analysis and evaluation" (2005) 25(3) Oxford Journal of Legal Studies 369-91, pp. 371-2.

26 Zaccaria, "Hermeneutics" (n. 1 above), pp. 266-7.

27 Ibid., p. 266, picking out MacCormick’s paper "Coherence” (n. 3 above). 
contradiction. What I say may be free of any internal inconsistency and yet fail to "hang together" or to "make sense" as a whole. ${ }^{28}$

In this way, and through a multitude of other accounts, the prevailing view emerges; that consistency in the negative aspect is necessary for coherence but is insufficient for it. ${ }^{29}$ So, nothing can be coherent that exhibits inconsistency, whatever further disputed and slippery elements are then added by particular theorists, but something could be consistent and fail to be coherent all the same.

Caution must be exercised, however. Many of those offering accounts of coherence do so with circumspection, carefully restricting their observations to particular cases, or to spheres within which coherence is to be used. Thus, Bertea appends to his comment above the footnote that,

It should be noted, here, by way of disclaimer, that this section is limited in scope to the argument from coherence (rather than to the concept of coherence). Therefore, only those contributions will be considered that impact directly on the definition and characterization of the argument from coherence. So the reader should not expect this to be anything like a comprehensive and exhaustive introduction to coherence. ${ }^{30}$

MacCormick, too, offers an account of coherence only in specific spheres, for whilst he states his aim is "to elucidate this elusive notion of "coherence", he never addresses this matter directly, examining instead "normative coherence" and "narrative coherence", particularly as these relate to legal justification. ${ }^{31} \mathrm{Be}$ this as it may, the sensible caution exhibited here still leaves standing whatever is said about coherence within these limited spheres, and what is said is that, in at least these spheres, consistency is a necessary but insufficient condition for coherence. Bertea is rightly wary of making more general claims to the concept of coherence, understanding that accounts offered in other spheres differ markedly from the account of it that he presents in his own topic field. This caution is not without its problems, however, as it is difficult to see what sense could be brought to the argument from coherence without addressing the concept of coherence first, just as little sense could be brought to an argument from prejudice without first picking out what prejudice is. Regardless, it is enough for the purpose of the present paper that the relevant modal claim is made, even if it is cautiously restricted to the sphere in which the writer has undertaken investigation.

Of consistency itself, little further is noted except to emphasise its employment in the logical sense - of an absence of self-contradiction. Pared down this way, there seems little

28 See MacCormick, "Coherence" (n. 3 above), p. 235.

29 This implies, of course, that coherence and consistency are distinct and distinguishable notions. I write of a "prevailing" view because it has occasionally been subject to criticism; thus, Wintgens concludes his paper "Coherence of the law" by stating boldly that "Consistency is not a necessary requirement of coherence." However, even here it turns out that the view is qualified in the relevant way, Wintgens writing that: "With the requirement of the systematic character of law, as expressed by the idea that consistency is a necessary condition of coherence, we nevertheless miss an important point. This is due to the fact that consistency as a necessary condition of coherence leaves the discussion on the level of theoretical reason alone. But in practical reasoning there can appear inconsistencies or incompatibilities between norms without the level of coherence of the system itself becoming too low. A perfectly coherent legal system must be consistent. This is a regulative idea. But, as a matter of course, no legal system is perfect in itself."; L Wintgens, "Coherence of the law" (1993) 79 Archiv fur Rechts und Sozialphilosophie 483-519, first quotation p. 514, second p. 485. So, "perfect" coherence in a legal system requires consistency. In similar vein, see the discussion of MacCormick at pp. 401-3 below and Kress at pp. 405-6 below.

30 See Bertea "The arguments" (n. 25 above), p. 371, n. 4.

31 See, e.g. MacCormick, Rhetoric (n. 3 above), pp. 229-33, section titled, "Narrative and normative coherence distinguished". 
to object to and, indeed, the elusive aspects of coherence are typically held to emerge only after this component is identified. So, presumably, where a witness asserts in oral testimony first $\mathrm{X}$ and then not-X, this self-contradiction dictates that coherence does not and cannot obtain, with whatever consequences are then taken to follow. No-one doubts that coherence and consistency are different concepts, but almost everyone writing in law accepts the necessary modal relation between the two. ${ }^{32}$

Even MacCormick's more recent, subtle approach to the relation in question finally accedes to the modality recorded elsewhere. He begins in unusual fashion:

I interpret consistency as being satisfied by non-contradiction. A set of propositions is mutually consistent if each can without contradiction be asserted in conjunction with every other and with their conjunction. By contrast, coherence, as I said, is the property of a set of propositions which, taken together, "makes sense" in its entirety. Complete consistency is not a necessary condition of coherence, since unlike consistency, coherence can be a matter of degree. ${ }^{33}$

These last observations appear to herald a move away from the orthodox position, for if complete consistency (in the sense of non-contradiction) is not necessary for coherence, then some room can be allowed for inconsistency whilst maintaining coherence itself. And this can be put more bluntly, as there appears to be nothing to separate consistency from "complete consistency" here, as the former notion depends upon the absence of self-contradiction in any event. Moreover, as MacCormick moves in his next sentence to distinguish the two core concepts on the further ground that "unlike consistency, coherence can be a matter of degree", there is still further reason for supposing that complete consistency and consistency simple are one and the same - as consistency cannot be a matter of degree. Thus, MacCormick would appear to commit to the bold view that "consistency is not necessary for coherence", thereby putting himself at odds with the view expressed elsewhere.

All this suggests a significant shift from MacCormick's earlier view, exemplified in the quotation from "Coherence in legal justification" provided above. The older formulation, although proposed specifically in relation to reasoning and to narrative and normative coherence in particular, nonetheless sits squarely with the orthodox general view, that consistency is a necessary but insufficient condition for coherence. As Zaccaria notes, MacCormick's view was that coherence "is something different from and more than mere consistency"34 (my italics). But this view cannot fully account for the practical examples produced in evidence by MacCormick in recent writing. Thus he observes that,

A story can be coherent on the whole and as a whole, though it contains some internal inconsistencies - and in this case, the sense of the overall coherence of a story may be decisive for us in deciding which among pairs of inconsistent propositions to disregard as anomalies in an overall coherent account or opinion. (Sometimes exact consistency in a story can be a ground of suspicion. For in trying to recall the past, people usually make some mistakes or have inexactness in memories, or two witnesses have a different perspective and do not quite coincide in what they say. Perfect consistency may therefore arouse suspicion that a concocted but untruthful story is being told.) ${ }^{35}$

32 See, e.g. Raz, "The relevance" (n. 3 above), who writes at p. 280: "What is incoherent is unintelligible, because it is self-contradictory, fragmented, disjointed. What is coherent is intelligible, makes sense, is well expressed, with all its bits hanging together."

33 MacCormick Rhetoric (n. 3 above), p. 190.

34 Zaccaria, "Hermeneutics" (n. 1 above), p. 266. The italics are mine. The orthodox relation can be found even earlier still, see MacCormick, "Legal Reasoning" (n. 3 above), p. 39 and p. 106.

35 MacCormick, Rhetoric (n. 3 above), p. 190. 
This is surely manifest good sense; after all, as the entire cinema knows, it is easy to smell a rat in The Manchurian Candidate, once all platoon members dutifully intone that "(Sergeant) Raymond Shaw is the kindest, bravest, warmest most wonderful human being I've ever met in my whole life." 36 And it is no less good sense in the legal arena - where in many applications, for example, witness statements at the scene, some inconsistency and confusion squares with the nature of unusual or extreme events seen quickly, in panic or anxiety. So some inconsistency, at least, might add to the coherence of a particular type of testimony. ${ }^{37}$ However, in a footnote worth recording in full, MacCormick then retreats from the position that seems naturally presaged (or even implied) in his foregoing remarks - that consistency is not necessary for coherence - writing:

Lamber M M Royakkers criticizes me for "deny[ing] the connection between consistency and coherence" . . . For avoidance of doubt, I should confirm that perfect coherence would require the elimination of all inconsistency, but some inconsistency is compatible with relative coherence, and it is one's grasp of relative coherence that in turn furnishes the ability to detect the inconsistencies that can and should be eliminated. 38

MacCormick thereby accepts that the elimination of all inconsistency is a precondition for perfect coherence; which is to say that perfect coherence requires perfect consistency. Similarly, some inconsistency is compatible with relative, that is some, coherence. So while MacCormick stops short of stipulating expressly that consistency is a necessary requirement for coherence, he accedes to this relation at least with regard to "perfect" coherence. But there is no need for MacCormick to confirm even this relation, and good reason that he shouldn't, as it doesn't even fit his own example.

\section{Three}

MacCormick's example reminds us that sometimes, at least, some inconsistency improves the coherence of a story. ${ }^{39}$ Perhaps this can only apply to certain types of story (for example, narratives related in testimony at trial) and not to others (for example, fairy tales), but its prospect is enough to deny the global conclusion that perfect coherence always requires "the elimination of all inconsistency". Instead, it is correct only to say that some types of story (fairy tales, say) require the elimination of all inconsistency for their coherence, whereas others do not (for instance, witness statements at the scene; the victim's testimony at trial). This is far from the slight distinction that it first appears, for the relation between coherence and consistency thereby becomes contingent rather than necessary. Flatly, whether consistency (in the sense of the absence of contradiction) is required for the coherence of some object turns out to be contingent upon the sort of object that is in question.

In fact, a moment's reflection is enough to put in doubt the perceived conceptual relation between coherence and consistency. The task is to find some case, any case, in which coherence is impeded by consistency or, indeed, depends positively upon some

36 The Manchurian Candidate, J Frankenheimer (dir.), MGM (USA 1962).

37 I anticipate an immediate and obvious complaint here: previously, we had in mind the coherence of witness testimony with regard to something like its consistency, etc taken as a whole; now, it appears, we are considering the coherence of witness testimony with regard to something like "our natural expectations of truthful testimony in particular cases". This, however, demonstrates precisely the point I aim to make. Thus, it is plain - indeed, axiomatic - that, with regard to the former context, consistency is a necessary feature, but it is equally plain, with regard to the latter, that, regarding our expectations of non-concocted witness testimony at the scene (at some scenes), it isn't. So consistency is necessary for the coherence of some objects, but not others. For the profound implications of this, see section Three below.

38 MacCormick, Rhetoric (n. 3 above), p. 190, n. 3.

39 For my caveat, see n. 37 above. 
inconsistency. It is worth noting, then, that all paradoxes depend upon the presence of some internal contradiction for their coherence; or again, that any argument between two disputants depends upon some contradiction for its coherence; and plainly, inconsistency is a necessary feature for the coherence of any set of contradictory propositions. What is more, the dramatic coherence of most fictional courtroom narratives (and real ones as well) depends upon at least some flat contradiction. It will naturally be objected that this is all smoke and mirrors: the reason why coherence depends in these cases upon the presence of inconsistency is due entirely to the nature of the (rather obscure) objects in question (for example, dramatic coherence). But then, that just demonstrates the point; it isn't that consistency is necessary for coherence, it's that consistency is necessary for the coherence of some (perhaps many) objects - and an impediment to the coherence of others. Moreover, the objects in question do not have to be obscure; there is nothing obscure about MacCormick's own example drawing on the testimony of witnesses.

Of course, it is open to those advocating consistency as a necessary requirement for coherence to attest that this is what they meant all along: when they aimed to elucidate coherence they really intended the coherence of a state's constitutional provisions, or the coherence of a legal normative order, or the coherence of elements led in inductive reason by counsel, suggesting to members of a jury what really happened on the night in question. But this is nowhere made apparent in the literature, and it is doubtful that it has in fact been noticed. Thus, examples such as that of MacCormick's witnesses are taken to present obstacles to the orthodox position, to be read down, awkwardly, into the standard view where in fact they could easily be distinguished on the simple ground that they concern different objects. ${ }^{40}$ More boldly, it might even be said that the perceived slipperiness and elusiveness of coherence itself is also accounted for just by the oversight in question.

Let's first be clear about the oversight: my argument, in formal terms, is that accounts of coherence routinely confuse the intension of the concept with one or more of its many extensions. Thus, theorists have tried to flush out necessary features of coherence by reflecting, consciously or otherwise, on what is required for the coherence of some object or set of objects. Because many of the legal theorists addressing coherence quite naturally have in mind legal reasoning or a legal normative order when bringing coherence into view, consistency is turned up as a necessary feature of coherence, just because it is a necessary feature of these objects. This is an easy mistake to make, but it has profound consequences. Consider the same method applied to the concept of completeness: one might reflect on motor-car completeness (on a production-line, say) and then draw the conclusion that "motorised" was part of the meaning of complete. Or one might take "reaching the summit" as part of the meaning of conquest - just where one has in mind mountain climbing. And of course, completeness and conquest would then seem complex and elusive when enquiry ranged over the completeness of crosswords (no motor) or the Norman Conquest of England (no mountainous ascent). In fact, the meaning of

40 Thus, MacCormick goes on to note that narrative coherence "requires that there be no inexplicable logical inconsistencies between any of its factual elements", and adds in a footnote: "The idea of an inexplicable inconsistency depends on the thought that a degree of inconsistency between witnesses or even in a single person's accounts of past events is to be expected, because memory and perception, especially in relation to traumatic events, are imperfectly reliable. Some mistakes or elements of vagueness may thus make a story more plausible, because they arouse less a suspicion that they have been 'cooked up' after the event. But after discounting explicable inconsistencies, what remains must be non-contradictory and satisfactorily coherent in what remains after the discounted elements are dropped out."; MacCormick, Rhetoric (n. 3 above), p. 226 and n. 13 on the same page. So MacCormick distinguishes the awkward case of witness inconsistency by adding a further test of explicable and inexplicable contradiction - but this still leaves some witness inconsistency (the explicable parts) fully compatible with coherence, explicability merely being invoked as a further test of truth or mendacity. 
coherence no more depends upon consistency than completeness depends upon being motorised, even though some objects will only be complete where they possess a motor, and some objects will only be coherent where they are also consistent. Rather, as should now be horribly clear, a motor is necessary for a complete motor car simply because motors are necessary features of motor cars (no motor car could be complete without one), and, similarly, no inductive argument pressed into service by counsel could be coherent if it contained contradiction . . . because consistency is a necessary requirement of such reasoning. Because inductive reason demands consistency, it follows rather obviously that coherent inductive reason demands consistency - but it would plainly be a terrible mistake to conclude from this that whatever is coherent must be consistent.

Thus, the spectre looms of a conceptual and practical train wreck, in which exhortations to coherence are delivered in increasing number, with each new invocation of coherence adding to the perceived slipperiness of the concept in question. For, just as e.g. coherent inductive reason depends certainly upon consistency, it also depends upon the presence of a conclusion, some premises, etc, and these further features of coherent inductive reason immediately make coherence appear elusive and contested when investigating other applications of coherence, even within the legal sphere alone. So we might find that the coherence of a statute has nothing whatever to do with the presence of a conclusion, or the coherence of witness testimony has little to do with the presence of legally authoritative norms, and so on, thereby leading inexorably to the view that a general account of coherence is slippery at best, if not impossible at worst, and causing the literature to retreat into ever more timid accounts of coherence, restricted to ever more diminutive pockets of application.

This, then, is the spectre. The train wreck I have in mind takes the preoccupation with consistency to be pivotal, just because the requirement of consistency compasses sufficient numbers of objects-that-cohere in law that the oversight in question can be maintained. So the differences imputed to coherence that in fact arise from straightforward distinctions between objects are understood, instead, as local disputes about what "something more" must be added to consistency for a (cautiously restricted) account of coherence itself. And objects that don't fit the modality at all (such as MacCormick's witness example) are to be read down into conformity with the relation, or can be excluded as aberration, or can quietly be forgotten altogether. This picture is so striking - and unlikely - that I need to provide some further evidence for it here, though my account can be tested most effectively simply by investigating its explanatory force in any of the invocations of coherence across the considerable range of its use in law. Therefore, I will restrict my demonstration in this section to the examination of one piece of writing that remains principally conceptual in form, reserving for the concluding section the examination of a commentary concerning coherence in relation to more substantive legal matters.

First, then, I will investigate Ken Kress's chapter entry, "Coherence", in A Companion to Philosophy of Law and Legal Theory. ${ }^{41}$ The choice of this piece is motivated precisely because of its clarity and simplicity, which is in part due to the introductory and explanatory context in which it appears. I am going to consider in detail just a few paragraphs from the chapter, taken from the part around and including Kress's section "What coherence is". There he notes:

To understand coherence in law, techniques thought to promote coherence, or properties or states thought to be aspects of, explanations of, or to be necessary or sufficient for coherence, will be examined. The discussion will focus on justificatory coherence within normative theory, particularly ethics and law,

41 Kress, "Coherence" (n. 3 above). 
although concepts more appropriate to the theory of knowledge will be discussed in passing. The primary aim throughout is to serve as background for the later taxonomy of coherence in normative theory, although much of what is said here applies more generally. 42

In Kress's approach it is immediately possible to perceive the same structure deployed throughout the literature in attempts to state what coherence is. So, to understand coherence in a particular context (here, in law in general), Kress sensibly considers that he should examine aspects of, explanations of, and necessary and sufficient conditions for, coherence. But he then informs us that this project will, in turn, focus on "justificatory coherence within normative theory, particularly ethics and law, although . . . theory of knowledge will be discussed in passing". Kress is astute in observing that his comments on coherence thereafter will have a range limited in this way, but his format is nonetheless prone to the methodological problems set out above, and its adoption already presages his conclusion about coherence in the next section:

From here on, the discussion is limited to coherence in moral, legal, and political theory, and would not necessarily apply to coherence theories of knowledge or truth. The remarks that follow are not intended to be a complete and final definition of coherence in normative theory. Coherence is much too difficult a concept for that. There is a range of conceptions of coherence, not just one. What is offered here is a first approximation of a taxonomy of conceptions of coherence. ${ }^{43}$

Again, Kress's observations just fall out naturally under his methodological premise, that coherence itself can be sought safely through the examination of objects that cohere. To nail down the point, Kress's cautious and methodologically reserved approach is unworkable from the outset, for the only sure way of distinguishing "necessary and sufficient" features of coherence from other features of the few objects in question is to have a secure idea of coherence in the first place. In the absence of such an understanding, enquiry is condemned to peer with ever-increasing attentiveness into the detail of the cohering objects in question, with no idea of the point at which abstracting coherence might stop. So, under this method the risk is always that coherence will prove immune from "final definition" as "too difficult a concept", and that conceptions will proliferate - coextensively, in fact, with the variety of instantiations of it that are surveyed in its investigation. Naturally enough, this then forces Kress to fall back on a "taxonomy of conceptions of coherence" as the way out of the resulting morass. Thus Kress's treatment exhibits all the characteristics of the oversight I pick out, referring cautiously to the coherence of (some) objects in accounting for coherence itself, and then retreating into a "range of conceptions of coherence, not just one", in response to the difficulty thereby perceived in the central concept.

Reflecting the orthodox view, consistency is one of three "possible necessary requirements for coherence" 44 considered under Kress's approach, and is indeed found to be necessary for coherence. He writes:

Consistency at a time is necessary in theory for normative coherence, but it is not sufficient for it. By normative coherence is meant a coherence theory in a normative area where the coherence requirements do substantial justificatory work. Consistency over time is not necessary for a coherence theory such as

42 Kress, "Coherence” (n. 3 above), pp. 539-40.

43 Ibid., p. 543.

44 Ibid., p. 540 . 
Dworkin's, which permits - indeed requires - change over time. Insofar as common-law adjudication is one of the features to be explained by coherence, the theory should not demand consistency or coherence amongst the principles of the theory at different times, but only a coherent path of movement over time (Kress, 1985). Finally, although consistency at a time is necessary in theory, or metaphysically, for coherence, it is not necessarily required in practice. Although we aim for consistency in the long run, modest scepticism may recommend that we do better day-to-day if we retain some inconsistencies until we are able to resolve them satisfactorily, rather than force consistency via ad hoc solutions. Given the difficulty of developing consistent, coherent, and complete theories and the value of experimentation, especially in a federal system, consistency (and coherence) are arguably less desirable and necessary in practice than as a regulative ideal (Sayre-McCord, 1985) . . 45

Kress appears to draw two conclusions about consistency in this paragraph, writing that "although consistency at a time is necessary in theory, or metaphysically, for coherence, it is not necessarily required in practice". However, these conclusions do not and cannot attach in the relevant way to the core concept itself, just because the investigation from which they are drawn once again analyses a thing-that-coheres (in this instance "normative coherence", which Kress informs us is "a coherence theory in a normative area"). The consequence is that even Kress's local and circumspect conclusions about coherence derive from features contingent to coherence itself, but which inhere in the particular object that he has in mind when bringing coherence into view. His treatment thereby becomes an inquiry into what features are necessary to a coherence theory in a normative area, and looked at this way, he produces the conclusion that consistency is not a necessary feature of the object in practice, though it is metaphysically. Indeed, it is worth noting that if Kress's conclusions were held determinedly to attach to coherence itself, an absurdity results, in which consistency is found to be both necessary for coherence, and not necessary for it. Once it is seen that the enquiry is really into the conditions for the coherence of two different objects (normative coherence in theory; normative coherence in practice) then the contradiction simply falls away: there is no difficulty in supposing that consistency might be necessary for some objects but not others. In short, if it turns out that consistency is a requirement for the coherence of ideal normative theory, then what has been uncovered is, prima facie, something about ideal normative theory, not the nature of coherence. Similarly, if it also turns out that consistency is not necessary for the coherence of normative practice, then, prima facie, this appears to record something about the nature of normative practice, not about the core concept in question. This presents a significant problem because, under Kress's analysis, "the most important differences between normative coherence theories" arise because of differences over "what coherence itself means". ${ }^{46}$ It follows that Kress's attempt to distinguish such theories through coherence is misplaced, and, indeed, his own enquiry into coherence simply reverts back to differences that are exhibited otherwise amongst the set of objects in question.

In the preceding analysis the cautious use of "prima facie" is warranted because something is uncovered about the nature of coherence if it is shown that any single object can be coherent whilst being inconsistent, for this shows that consistency is not necessary for coherence. So, if Kress can show that normative practice need not be consistent and yet remain coherent, then he would have a strong case for the rejection of consistency as a necessary characteristic of coherence simple. Kress does not point us to this potential in his

45 Kress, "Coherence" (n. 3 above), p. 540.

46 Ibid., p. 537 (quoted on pp. 397-8 above). 
method, drawing a more circumspect conclusion about coherence (and its relation to consistency) that attaches just to the instance of it in question (ideal normative coherence; normative coherence in practice), and this circumspection is once again a problem attributable to the persistent idea that coherence is to be understood and pursued through, and thus limited to, things-that-cohere.

I have tried to show that Kress's account of coherence (and thus of coherence in law), succumbs to the methodological oversight I pick out. I have also attempted to show, at least in Kress's account, that the oversight causes unnecessary circumspection (in drawing modal conclusions), unnecessary circumlocution (in acceding to a taxonomy of coherences), and leads finally to conceptual frustration, in perceiving coherence to be too difficult for simple elucidation. In fact, none of these things are attributable to coherence itself, but have everything to do with the method pressed into service in its investigation.

What, then, of coherence itself? Once freed from consistency, a simple, general and clear account of coherence can be provided, as might be anticipated by the intuitive grasp of the concept we all employ in its everyday use. In short, coherence seems to mean, and indeed could only usefully mean, "sticking together". Happily, understanding coherence this way is consistent with the etymology of "co-" (together), plus "baerere" (to stick), and is, in any case, the single feature uniformly recorded of the concept in dictionary definition (though dictionaries typically provide a variety of further features claimed to inhere in the notion). So, on my simple account, if an argument is said to cohere, then what is proposed is that it sticks together. If a sentence coheres, then it, too, sticks together. Similarly, if one statute coheres with another, then they stick together. Exactly how these or any other objects stick together, if indeed they do, is then a separate matter and one that depends, rather obviously, on various properties or qualities of the particular objects in question. So, whatever it is that causes light waves to cohere, where they do, ${ }^{47}$ is likely to be very different from the factors involved in the coherence of a pair of sentences, this differing in turn from the set of factors determining whether an argument is coherent, and so on.

Of course, more could be said about coherence as sticking together, but perhaps only one thing is necessary here, as the account is offered just as a supplement to the principal analysis, without prejudice to the methodological criticism I propose above. It might be thought that "sticking together" pares the meaning of coherence down so far that the concept loses all practical import. This is not the case at all; in fact, coherence understood this way remains a seriously robust and useful concept, the natural adjunct to other similarly useful concepts such as adherence and inherence. Thus, just where adherence means "sticking to" (and inherence means "sticking in") so coherence indicates a relation of symmetrical sticking - of mutual or reciprocal adherence. In fact, the impulse to attach this solid relation to some further feature or features found in its use undoes the usefulness of the concept in the way indicated in the foregoing discussion. It is to this latter feature that analysis now returns, taking as the subject of the last section the implication of the preceding commentary in substantive application in the legal sphere.

\section{Four}

To the preceding commentary could be retorted a resounding "So what?". People offering accounts of coherence in law do so to explicate something about the nature of law, or to urge more coherence in a particular legal field, or in a particular legal method, so it should matter little that the coherence in question is actually coherence in evidential reasoning, or

47 See, e.g. L Mandel. and E Wolf, Optical Coherence and Quantum Optics (Cambridge: CUP, 1995): light waves exhibit coherence where these waves are in perfect phase relation with each other. 
the coherence of private law, or whatever. This is a fair point; much (and perhaps most) writing on coherence in law will be immune from criticism in just this way. But the immunity is bought at a considerable price, deflating the utility of coherence to a point which is difficult to reconcile with the expansive body of coherence literature now in play. If exhortations to greater narrative coherence at trial really deflate to questions of what narrative is, or what narrative-at-trial amounts to, or to what works best at trial, then the reasons for the intercession of coherence begin to look shaky indeed. The difficulty is that coherence just seems redundant; it's everywhere you look, but when you look really hard, it just melts away. Worse, the invocation to coherence seems to promise much more, and so there may be real currency in the idea that it seems to do so much precisely because it is understood so little. I am just going to focus on the redundancy of coherence in what follows, taking an example used by MacCormick "to give ample illustration of the force of narrative coherence". 48

The example is taken from the Sherlock Holmes case of the dog that did not bark, ${ }^{49}$ and bears on substantive legal matters such as reasoning to a conclusion from circumstantial evidence alone, or to the methods that might profitably - and justifiably - be employed by police and other services in the field of criminal investigation. Of the story itself, MacCormick writes:

The case of the dog that did not bark in the night is in point. A valuable race horse has been taken from the stable by night. The trainer has been found dead on the Downs nearby. A suspicious-looking stranger has been picked up by the police and held on a murder charge. But Sherlock Holmes elicits from reliable witnesses the information that they did not hear the stables' dog barking by night. "The dog did not bark" and "a stranger took the horse" are not mutually contradictory. Yet if, as a generalization, dogs bark at strangers, then, under this common-sense principle, the dog's not barking becomes incompatible with a stranger's taking the horse, unless there is some further explanation, or some relevant exception to the common-sense generalization. ${ }^{50}$

MacCormick takes narrative coherence (here as elsewhere) to provide "a test as to the truth or probable truth of propositions about unperceived things and events", concluding that "Such a test justifies beliefs." 51 My analysis suggests that the role coherence plays here is much more diminutive that it appears.

Bluntly, coherence furnishes no test at all in the story in question, for the police reasoning to the suspicious stranger is manifestly coherent, though simple-minded - as is typical in the Holmes stories taken here and as a whole ("sudden unusual happening" and "new suspicious-looking stranger" fit quite well together, just as they stand). Nor is it coherence that leads Holmes to his more justified conclusion; instead it is just that he asks a further question, and the response to this creates a new narrative element - that is, creates a new story. Perhaps the police explanation does not cohere with the new set of narrative

48 MacCormick, Rhetoric (n. 3 above), p. 225 n. 12.

49 A Conan Doyle, "Silver Blaze" in The Memoirs of Sherlock Holmes (1892).

50 MacCormick, Rhetoric (n. 3 above), p. 225, n. 12.

51 Ibid., both quotations at p. 226. MacCormick says much more about narrative coherence than this, and in particular asserts that it may only weakly justify conclusions, but it has justificatory force all the same. 
elements (it doesn't), but this indicates nothing about the coherence - or even relative coherence - of the police's former reasoning. Indeed, a super-detective might be imagined who goes further still than Holmes, and who elicits the information from reliable witnesses that the dog had been to the vet that day, and in consequence of medication could not hear a thing (and so on - the police perhaps turning out to have got the right man all along). So it cannot be coherence that determines between the police's explanation and that of Holmes, as both are highly coherent as they stand, but it's obvious to all of us that Holmes's provides the better story: there's not much literary mileage, presumably, in The Collected Cases of Inspector Lestrade. ${ }^{52}$

In short, there are two coherent objects in question in the Holmes story, one of which is plainly to be preferred, narratively speaking. What prises the explanations apart is our preference for some narratives over others, not coherence at all. We can put this in terms of coherence (as we can with almost anything) ${ }^{53}$ but not much is added; the matter of determining narrative coherence still turns out to be a matter of determining which of two rivals strikes us as the better narrative. Prima facie, then, it would seem better to strike coherence out altogether and deal direct with narrative itself, particularly in light of the frustration and doubt so evidently caused by the former concept. Indeed, a pragmatist (or practitioner) would be advised, when considering the literature as a whole, to test coherence in any putative application, by putting a line through it and then reflecting on what has actually been lost. Plainly, a thorough inspection of the literature cannot be offered here, and doubtless many applications of coherence in law remain robust and sensible once they are investigated in this way - but some, however, will not. This alone should provide reason for serious prudence in deliberating the application of the concept.

Whatever is found about the utility of coherence in legal application, I aim at least to have shown that the frustration concerning coherence itself is unwarranted; coherence is much simpler (and actually then, more useful) than is routinely supposed. It is telling indeed that even where coherence is pursued cautiously, restricted only to particular spheres, no attempt is made to deliberate how features of such localised coherence are to be untangled from features of the context otherwise - though this might be expected in opening methodological treatment. In short, evidence of the oversight in question appears everywhere. Once freed of consistency and other characteristics wrongly imputed to it, coherence becomes available for properly general use, understood sufficiently clearly to allow the benefits of its application to be weighed appropriately. And, hopefully, these clarifications go some way towards furnishing an account of coherence that the troops can use in the field.

52 Inspector Lestrade is a fictional police officer from Scotland Yard, who appears in several of the Holmes stories, acting as a bluff, pragmatic foil to Holmes's incisive and creative reason. (In fact, the author M J Trow has written a series of novels with Lestrade as the main character, but in these it turns out that the prosaic inspector is a more acute and subtle figure than allowed for by Conan Doyle.)

53 Here, for example, we might (again) deploy "dramatic coherence"; see p. 402-3 above. 
